\title{
(18)FDG-PET-CT improves specificity of preoperative lymph-node staging in patients with intestinal but not diffuse-type esophagogastric adenocarcinoma
}

\author{
Lehmann, K ; Eshmuminov, D ; Bauerfeind, P ; Gubler, C ; Veit-Haibach, P ; Weber, A ; \\ Abdul-Rahman, H ; Fischer, M ; Reiner, C ; Schneider, P M
}

\begin{abstract}
INTRODUCTION The accuracy of preoperative lymph-node staging in patients with adenocarcinoma of the esophagogastric junction (AEG) or gastric cancer (GC) is low. The aim of this study was to assess the accuracy of [18F]fluorodeoxyglucose positron emission tomography/computed tomography (PET-CT) for lymph-node staging in patients with AEG or GC, with or without neoadjuvant treatment. PATIENTS AND METHODS 221 consecutive patients with GC $(\mathrm{n}=88)$ or AEG $(\mathrm{n}=133)$ were evaluated. Initial staging included endoscopic ultrasound (EUS), multidetector spiral CT (MDCT) and PET-CT. PET-CT was performed for restaging in patients after neoadjuvant treatment $(\mathrm{n}=94)$. Systematic lymphadenectomy was routinely performed with histopathological assessment of individual mediastinal and abdominal lymph-node stations. Preoperative staging from EUS, MDCT, and PET-CT was correlated with histopathological results. RESULTS PET-CT showed a high specificity (91\%) and positive predictive value $(89 \%)$ for the preoperative detection of lymph-node metastases. In comparison, EUS was more sensitive $(73 \%$ versus $50 \%, \mathrm{P}<0.01)$ but less specific $(60 \%, \mathrm{P}<0.01)$. In patients with intestinal/mixed-type tumors, PET-CT improved the detection of extra-regional lymph-node metastases $(\mathrm{P}=0.01)$ and distant metastases $(\mathrm{P}=0.01)$ compared to $\mathrm{CT}$ alone. In contrast, lymph-node assessment by $\mathrm{PET} / \mathrm{CT}$ after neoadjuvant treatment $(32 \%, \mathrm{P}<0.01)$ and in diffuse-type cancers $(24 \%, \mathrm{P}<0.01)$ is futile because of low sensitivities. CONCLUSION PET-CT does not improve the overall accuracy of $\mathrm{N}$ staging, but does improve specificity compared to EUS and MDCT in AEG and GC. We do not recommend routine PET-CT for the initial staging in patients with diffuse-type cancer or for restaging of lymph nodes after neoadjuvant treatment.
\end{abstract}

DOI: https://doi.org/10.1016/j.ejso.2016.08.020

Posted at the Zurich Open Repository and Archive, University of Zurich

ZORA URL: https://doi.org/10.5167/uzh-126464

Journal Article

Accepted Version

Originally published at:

Lehmann, K; Eshmuminov, D; Bauerfeind, P; Gubler, C; Veit-Haibach, P; Weber, A; Abdul-Rahman, H; Fischer, M; Reiner, C; Schneider, P M (2017). (18)FDG-PET-CT improves specificity of preoperative lymph-node staging in patients with intestinal but not diffuse-type esophagogastric adenocarcinoma. European Journal of Surgical Oncology, 43(1):196-202.

DOI: https://doi.org/10.1016/j.ejso.2016.08.020 


\title{
${ }^{18}$ FDG-PET-CT improves specificity of preoperative lymph-node staging in patients with intestinal but not diffuse-type esophagogastric adenocarcinoma
}

\author{
K. Lehmann ${ }^{\text {a }}$, D. Eshmuminov ${ }^{\text {a }}$, P. Bauerfeind ${ }^{\mathrm{c}}$, C. Gubler ${ }^{\mathrm{c}}$, \\ P. Veit-Haibach ${ }^{\mathrm{b}}$, A. Weber ${ }^{\mathrm{d}}$, H. Abdul-Rahman ${ }^{\mathrm{a}}$, M. Fischer ${ }^{\mathrm{e}}$, \\ C. Reiner ${ }^{\mathrm{e}}$, P.M. Schneider ${ }^{\mathrm{f}, *}$ \\ ${ }^{a}$ Department of Visceral and Transplantation Surgery, University Hospital Zurich, Switzerland \\ ${ }^{\mathrm{b}}$ Department of Nuclear Medicine, University Hospital Zurich, Switzerland \\ ${ }^{\mathrm{c}}$ Department of Gastroenterology, University Hospital Zurich, Switzerland \\ ${ }^{\mathrm{d}}$ Institute of Clinical Pathology, University Hospital Zurich, Switzerland \\ ${ }^{\mathrm{e}}$ Institute of Diagnostic and Interventional Radiology, University Hospital Zurich, Switzerland \\ ${ }^{\mathrm{f}}$ Surgical Center Zurich for Visceral, Thoracic and Specialized Tumor Surgery, Hirslanden Medical Center, \\ Zurich, Switzerland
}

Accepted 12 August 2016

Available online

\begin{abstract}
Introduction: The accuracy of preoperative lymph-node staging in patients with adenocarcinoma of the esophagogastric junction (AEG) or gastric cancer (GC) is low. The aim of this study was to assess the accuracy of [18F]fluorodeoxyglucose positron emission tomography/ computed tomography (PET-CT) for lymph-node staging in patients with AEG or GC, with or without neoadjuvant treatment.

Patients and methods: 221 consecutive patients with GC $(\mathrm{n}=88)$ or AEG $(\mathrm{n}=133)$ were evaluated. Initial staging included endoscopic ultrasound (EUS), multidetector spiral CT (MDCT) and PET-CT. PET-CT was performed for restaging in patients after neoadjuvant treatment $(\mathrm{n}=94)$. Systematic lymphadenectomy was routinely performed with histopathological assessment of individual mediastinal and abdominal lymph-node stations. Preoperative staging from EUS, MDCT, and PET-CT was correlated with histopathological results.

Results: PET-CT showed a high specificity $(91 \%)$ and positive predictive value $(89 \%)$ for the preoperative detection of lymph-node metastases. In comparison, EUS was more sensitive $(73 \%$ versus $50 \%, P<0.01)$ but less specific $(60 \%, P<0.01)$. In patients with intestinal/mixed-type tumors, PET-CT improved the detection of extra-regional lymph-node metastases $(P=0.01)$ and distant metastases $(P=0.01)$ compared to CT alone. In contrast, lymph-node assessment by PET/CT after neoadjuvant treatment $(32 \%, P<0.01)$ and in diffuse-type cancers $(24 \%, P<0.01)$ is futile because of low sensitivities.

Conclusion: PET-CT does not improve the overall accuracy of $\mathrm{N}$ staging, but does improve specificity compared to EUS and MDCT in AEG and GC. We do not recommend routine PET-CT for the initial staging in patients with diffuse-type cancer or for restaging of lymph nodes after neoadjuvant treatment.
\end{abstract}

(C) 2016 Published by Elsevier Ltd.

Keywords: Gastric cancer; PET-CT; Preoperative staging

Abbreviations: AEG, adenocarcinoma of the esophagogastric junction; CT, computed tomography; EUS, endoscopic ultrasound; GC, gastric cancer; LAD, lymphadenectomy; LN, lymph node; MDCT, multidetector spiral computed tomography; PET, 18 -fluorodeoxyglucose $\left({ }^{18} \mathrm{FDG}\right)$ positron emission tomography; PET-CT, combined positron emission tomography and computed tomography.

* Corresponding author. Surgical Center Zurich for Visceral, Thoracic and Specialized Tumor Surgery, Hirslanden Medical Center, Witellikerstrasse 40, 8032 Zurich, Switzerland.

E-mail address: paul@professor-schneider.ch (P.M. Schneider).

\section{Introduction}

Adenocarcinomas of the stomach (gastric cancer, GC) and esophagogastric junction (AEG) (types I-III according to the Siewert classification ${ }^{1}$ ) are among the most lethal tumors worldwide. ${ }^{2,3}$ Lymph-node status is a major prognostic factor, ${ }^{4}$ and the influence of extended 
lymphadenectomy (LAD) has been studied in, for example, patients with Barrett's cancer (AEG Siewert type I). In these patients, two-field LAD, including the abdominal and mediastinal nodes, resulted in a survival advantage of approximately $10 \%, 5$ and was significant when up to eight positive lymph nodes were present. ${ }^{6}$ In a Dutch randomized trial $^{7}$ in patients with gastric cancer, D2-LAD, compared to D1-LAD, reduced locoregional recurrence rates and resulted in a significant survival benefit after 15 years of follow-up.

Current preoperative staging includes endoscopic ultrasound (EUS), multidetector spiral computed tomography (MDCT),${ }^{8,9}$ and laparoscopy prior to neoadjuvant treatment for locally advanced GC and AEG Siewert types II-III. ${ }^{10}$ EUS is considered the most accurate diagnostic modality for determining tumor invasion ( $\mathrm{T}$ category), although the accuracy depends on the examiner's experience, and evaluation of distant lymph-node stations is not possible. ${ }^{11,12}$ Despite a known low sensitivity and specificity, $\mathrm{CT}$ is performed for the assessment of lymph nodes and metastases ( $\mathrm{N}$ and $\mathrm{M}$ categories). ${ }^{13}$ In the current clinical setting, prediction of lymph-node involvement is therefore poor, with a low overall accuracy, and low positive and negative predictive values. ${ }^{8}$

PET alone may be of additional diagnostic value when compared to CT because of its higher specificity, demonstrated in some series. ${ }^{14,15}$ However, the main disadvantage of PET is the low overall sensitivity and spatial resolution. It is therefore not yet clear whether PET is useful for staging in every patient. ${ }^{13}$ Metabolic response assessment of the primary tumor in patients receiving neoadjuvant therapy correlated with an improved survival after resection. ${ }^{16}$ This prognostic information is interesting for a subset of patients. However, it is unclear whether a PET-based restaging would allow adaptation of the surgical strategy. So far, EUS has already been demonstrated to be of little use for restaging after neoadjuvant treatment. ${ }^{17}$ The availability of combined PET-CT scanners provides simultaneous information about anatomy and cancer metabolism in one image, and may therefore improve anatomical assignment of PET signals and preoperative decision-making: i.e. selection of patients for preoperative chemotherapy or chemoradiation, ${ }^{18,19}$ targeted or systematic extension of $\mathrm{LAD},{ }^{20,21}$ limited versus systematic resection in patients with early cancer, ${ }^{22-24}$ or sophisticated individually tailored approaches. ${ }^{25}$

The aim of this study was to determine the staging accuracy of combined PET and CT, compared to EUS and MDCT, for $\mathrm{N}$ staging of patients with AEG and GC (with or without neoadjuvant treatment) in a large Western series.

\section{Patients and methods}

Patients referred to our institution during the years 2008-2013 with a biopsy-proven adenocarcinoma of the stomach or AEG Siewert types I-III were included. Exclusion criteria comprised previous treatment for AEG or GC, or any previous malignancy. Patients underwent routine staging procedures - including medical history, physical examination, laboratory tests, upper gastrointestinal endoscopy with EUS, MDCT, and PET-CT for initial staging - and were presented in a specialized upper gastrointestinal tumor board. Locally advanced tumors received neoadjuvant chemotherapy $\left(\mathrm{ECF}^{18}\right.$ or $\mathrm{FLOT}^{26}$ ) or chemoradiation, ${ }^{27}$ and were restaged by PET-CT 2 weeks after the last chemotherapy cycle and 4-5 weeks after chemoradiation.

The study was approved by the local ethics committee.

\section{Surgery}

Standardized resections were performed, including systematic D2 lymphadenectomy (LAD) with individual pathological assessment of lymph-node (LN) stations 1-12 (Japanese Gastric Cancer Association), ${ }^{28}$ and additionally LAD of the lower mediastinum for AEG types II and III. The D1 compartment includes perigastric LN stations 1-6; D2 includes stations 7-12 along the celiac axis. In patients with AEG Siewert type I, a transthoracic en bloc esophagectomy together with a two-field lymphadenectomy (extended mediastinal LAD) was the surgical standard. ${ }^{5}$ All LNs were separately labeled during the operation according to their localization in the mediastinum (Japan Esophageal Society) and abdominal LN compartments (Japanese Gastric Cancer Association) by P.M.S, who was present at all operations. LNs outside regional compartments - e.g. the axillary, supraclavicular, or para-aortic - were considered as "extra-regional" LNs (TNM 7th Edition, AJCC/UICC). ${ }^{29}$ Extra-regional LNs were biopsied by ultrasound or EUSguided fine-needle aspiration, or dissected during surgery if enlarged ( $\geq 10 \mathrm{~mm}$ ) or PET positive on preoperative scans.

\section{Endoscopic ultrasound}

EUS procedures were performed by two gastroenterologists (P.B. and C.G.) with Olympus echoendoscopes GF UE 160 (ALOKA, Holding Europe, Zug, Switzerland) with a $360^{\circ}$ radial scanner $(5-10 \mathrm{MHz}$, balloon contact method) in combination with an Aloka ProSound alpha 10. An LN was considered metastatic if the following criteria were present: hypoechogenic internal echo pattern, sharp borders and rounded shape, or a diameter $\geq 10 \mathrm{~mm}^{30}$

\section{Imaging by multidetector spiral computed tomography}

Contrast-enhanced MDCT was performed using a 128slice dual-source CT (Somatom Definition Flash, Siemens Healthcare, Forchheim, Germany) or a 64-slice dualsource CT (Somatom Definition, Siemens Healthcare, Forchheim, Germany) in all patients. LNs were considered positive if the short-axis diameter was $\geq 10 \mathrm{~mm}{ }^{31}$ 


\section{Imaging by ${ }^{18} F D G$ positron emission tomography}

PET-CT imaging was performed as a clinical procedure on an in-line system (Discovery LS or Discovery ST; GE Healthcare). These systems integrate a PET scanner (Advance Nxi; GE Healthcare) with a multi-slice helical CT (LightSpeed Plus or LightSpeed 16; GE Healthcare) allowing for acquisition of co-registered CT and PET images in one session. In PET-negative tumors, LNs were considered metastatic according to the criteria used for CT (short-axis diameter $\geq 10 \mathrm{~mm}$ ) whereas in PETpositive tumors only LNs with FDG uptake were considered positive.

\section{Statistical analysis}

Data were prospectively collected and entered in an SPSS database (Version 18.0, Chicago, IL). For categorical variables the chi-square or Fischer's exact test were used. All statistical tests were two-sided. All statistical analyses were performed using SPSS (Version 18.0, Chicago, IL). A $P$-value $<0.05$ indicated statistical significance.

\section{Results}

\section{Patient characteristics}

Two hundred and twenty-one consecutive patients with adenocarcinoma of the stomach or esophagogastric junction (Siewert type I-III) were included in this study (Table 1). The majority of patients presented with advanced (T2-4) tumors; only 46 patients (21\%) had early cancer, defined by tumor invasion limited to the mucosa/submucosa (uT1) on EUS. Ninety-four patients (43\%) received 3-4 cycles of neoadjuvant chemotherapy or chemoradiation. Surgery was finally performed in 193 patients; 28 patients had palliative treatment only because of systematic metastases or peritoneal carcinomatosis (Supplementary Fig. 1).

\section{PET-CT imaging of the primary tumor}

Overall, PET-CT detected the primary tumor in $79 \%$ of patients. Higher detection rates were found for AEG $(86 \%)$ compared to GC (70\%, $P<0.01)$, and for intestinal/mixedtype tumors compared to diffuse-type cancers according to Laurén's classification ( $86 \%$ versus $63 \%, P<0.01$ ).

\section{PET-CT for preoperative lymph-node staging}

Lymph-node staging by EUS, MDCT, and PET-CT was compared and correlated to staging by histopathology. Overall, EUS demonstrated the highest sensitivity (73\%) in detecting positive LNs compared to PET-CT (50\%) and MDCT (48\%). However, PET-CT had a higher specificity $(91 \%)$ and positive predictive value $(90 \%)$ compared to EUS and MDCT (Fig. 1). The low accuracy and
Table 1

Clinicopathological features (TNM 7th Edition, AJCC/UICC). ${ }^{29}$ Overall, 193 patients underwent tumor resection. Radical lymphadenectomy was defined as $\geq \mathrm{D} 2$ for gastric cancer or two-field lymphadenectomy for AEG I.

\begin{tabular}{|c|c|c|}
\hline Parameter & $\mathrm{n}=221$ & $\%$ \\
\hline Age (median, years) & 62 & \\
\hline \multicolumn{3}{|l|}{ Gender } \\
\hline Male & 158 & 71 \\
\hline Female & 63 & 29 \\
\hline \multicolumn{3}{|l|}{ Localization } \\
\hline AEG Siewert Type I & 66 & 30 \\
\hline AEG Siewert Type II & 38 & 17 \\
\hline AEG Siewert Type III & 29 & 13 \\
\hline Gastric cancer & 88 & 40 \\
\hline \multicolumn{3}{|l|}{ Grading } \\
\hline G1 & 7 & 3 \\
\hline $\mathrm{G} 2$ & 86 & 40 \\
\hline G3 & 128 & 58 \\
\hline \multicolumn{3}{|l|}{ Laurén's classification } \\
\hline Intestinal & 138 & 62 \\
\hline Mixed & 26 & 12 \\
\hline Diffuse & 57 & 26 \\
\hline \multicolumn{3}{|l|}{ Depth of invasion (EUS) $(n=193)$} \\
\hline uT1 & 46 & 21 \\
\hline uT2 & 54 & 24 \\
\hline uT3 & 74 & 34 \\
\hline uT4 & 19 & 9 \\
\hline \multicolumn{3}{|l|}{ Histopathologic T category $(n=193)$} \\
\hline урт0 & 8 & 4.1 \\
\hline pT1 & 59 & 30.5 \\
\hline pT2 & 31 & 16.0 \\
\hline pT3 & 76 & 39.4 \\
\hline pT4 & 19 & 9.8 \\
\hline \multicolumn{3}{|l|}{ Histopathological N category $(n=193)$} \\
\hline $\mathrm{pN}+$ & 112 & 58 \\
\hline pNO & 81 & 42 \\
\hline \multicolumn{3}{|l|}{ Metastatic disease } \\
\hline Extra-regional LN & 23 & 10.4 \\
\hline Hematogenic metastases & 24 & 10.2 \\
\hline Peritoneal metastases & 22 & 10 \\
\hline \multicolumn{3}{|l|}{ Type of surgery $(n=193)$} \\
\hline Transthoracic esophagectomy & 45 & 23 \\
\hline Transmediastinal esophagectomy & 19 & 10 \\
\hline Transhiatally extended gastrectomy & 62 & 32 \\
\hline Total gastrectomy & 21 & 11 \\
\hline Subtotal (4/5) gastrectomy & 46 & 24 \\
\hline \multicolumn{3}{|l|}{ Lymphadenectomy } \\
\hline Patients with $\geq \mathrm{D} 2$ or two-field LAD & 177 & 92 \\
\hline Number of harvested lymph nodes (median) & 36 & \\
\hline
\end{tabular}

predictive values were disappointing for all three modalities and did not translate into clinically relevant differences. Looking at the 108 patients that were directly operated, PET-CT showed a lower sensitivity of $35 \%$, as shown in Fig. 1, indicating that this group of patients includes earlier stages than patients with neoadjuvant therapy.

\section{Restaging of lymph nodes by PET-CT after neoadjuvant therapy}

Ninety-four patients received neoadjuvant treatment. We compared the lymph-node status on the initial PET-CT 


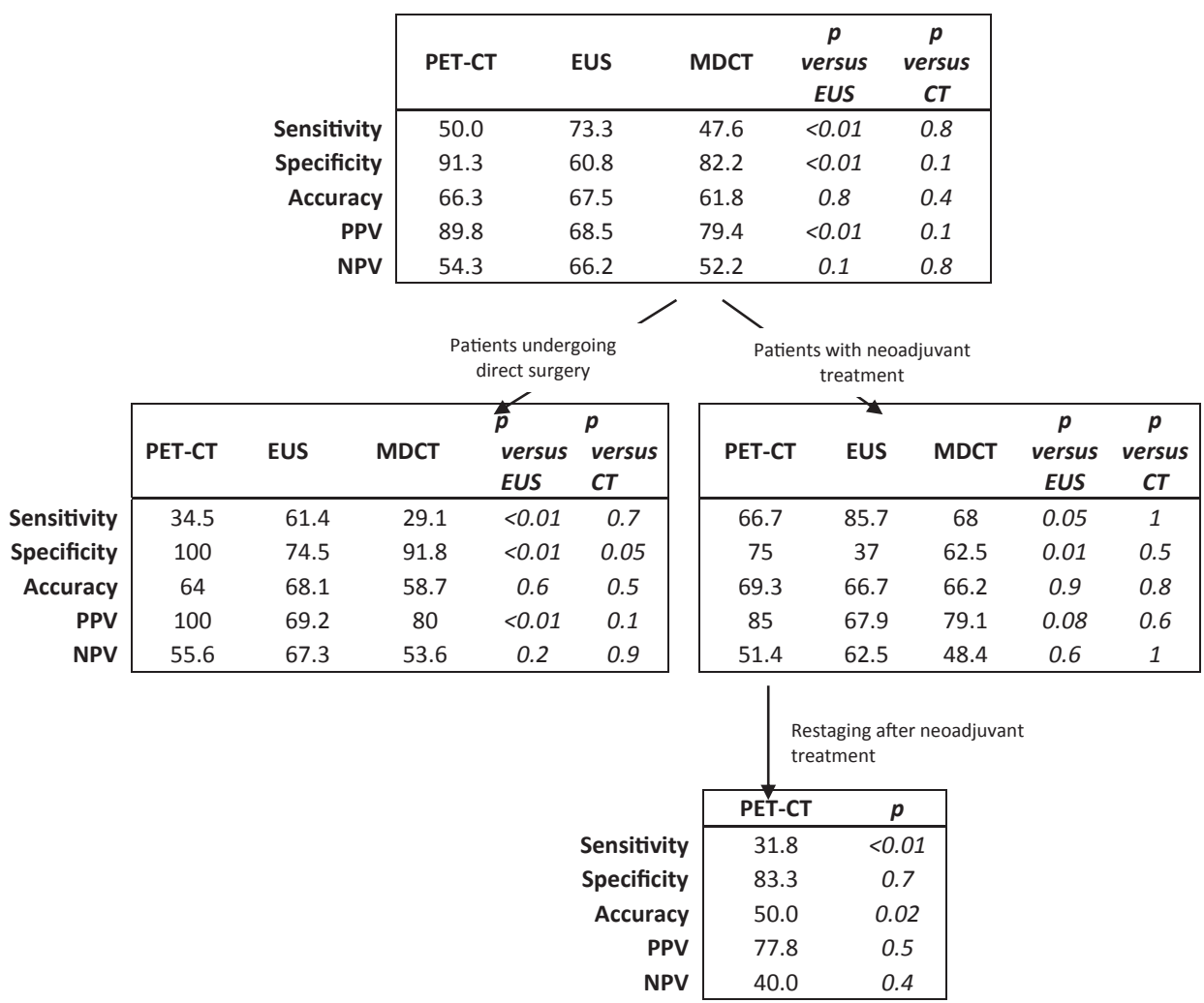

Figure 1. N staging by positron emission tomography and computed tomography (PET-CT), endoscopic ultrasound (EUS) and multidetector spiral computed tomography (MDCT). Preoperative lymph-node staging was evaluated by PET-CT, EUS and MDCT, and compared to staging by histopathology. Analysis was performed for the whole cohort of patients using initial staging results, then separately using initial staging for the groups with and without neoadjuvant treatment, and finally restaging PET-CT following neoadjuvant treatment prior to surgery.

prior to chemotherapy or chemoradiation to a second PETCT performed for restaging (Fig. 1). After neoadjuvant treatment, LNs became PET-CT-negative in 37\% of patients. Consequently, in the second PET-CT, the falsenegative rate increased, and the sensitivity dropped to only $32 \%(P<0.001)$ compared to the initial staging PET-CT. N staging in patients with neoadjuvant treatment should therefore always be interpreted on the basis of the initial PET-CT staging.

\section{$N$ staging according to tumor localization and Laurén's subtypes}

We compared the accuracy of $\mathrm{N}$ staging by PET-CT for different tumor locations, and found a higher sensitivity (62\% versus $38 \%, P=0.01$ ) and accuracy (72\% versus $49 \%, P=0.07)$ for AEG tumors compared to gastric cancer (Table 2). AEG-type tumors showed a higher rate of intestinal-type carcinomas compared to GC. Indeed, looking at the Laurèn type, the accuracy of $\mathrm{N}$ staging for intestinal/mixed-type tumors was significantly better than for diffuse-type tumors (Table 2). Additionally, we assessed whether PET-CT improves staging in a specific lymph-node compartment. However, we found only a poor accuracy in the D1 and D2 compartments.

\section{PET-CT in the staging of early cancer}

Despite a negative predictive value of $79 \%$, PET-CT did not detect small positive LN metastases in ten patients; three of them had micrometastases. Compared to MDCT,

Table 2

$\mathrm{N}$ staging according to tumor localization and Laurén's subtypes. Lymphnode staging by combined positron emission tomography and computed tomography (PET-CT) was assessed in adenocarcinoma of the esophagogastric junction (AEG) versus gastric cancer (A), and in intestinal versus diffuse-type carcinomas (B). Mixed types were grouped within intestinal types.

\begin{tabular}{llll}
\hline A & AEG I-III & Gastric cancer & $P$ \\
\hline Sensitivity & 61.8 & 38.3 & 0.01 \\
Specificity & 85.7 & 91.9 & 0.5 \\
Accuracy & 70.9 & 58.8 & 0.08 \\
PPV & 87.5 & 88.5 & 1 \\
NPV & 58.1 & 47.9 & 0.3 \\
\hline B & Intestinal & Diffuse & $P$ \\
\hline Sensitivity & 58.6 & 24 & $<0.01$ \\
Specificity & 88.9 & 100 & 0.6 \\
Accuracy & 71.8 & 48.6 & 0.02 \\
PPV & 87.2 & 100 & 1 \\
NPV & 62.3 & 38.7 & 0.03 \\
\hline
\end{tabular}

PPV, positive predictive value; NPV, negative predictive value. 
PET-CT therefore did not improve lymph-node staging in pT1 tumors (Table 3).

\section{PET-CT for extra-regional lymph nodes and systemic metastases}

Overall, there was no difference in the detection rate for systemic metastases by PET-CT and MDCT (Table 4). The main reason for this, despite a high specificity of both modalities, was missed peritoneal carcinomatosis. When peritoneal metastasis was excluded, the sensitivity of PET-CT increased significantly compared to that of MDCT $(82 \%$ versus $48 \%, P=0.01$, Table 4 ). Analyzing only the PETsensitive intestinal/mixed-type tumors, the sensitivity for detecting LN metastases outside regional compartments further increased and was significantly better for PET-CT than for MDCT (95\% versus $63 \%, P=0.01$ ).

\section{Discussion}

Our data confirm the moderate diagnostic value of EUS and $\mathrm{CT}$ in preoperative $\mathrm{N}$ staging for AEG and GC in this Western series. The major benefit of the combined PET-CT is a higher specificity and positive predictive value, particularly in intestinal/mixed-type tumors. In contrast, staging of diffuse-type tumors by PET-CT and evaluation of lymph nodes after neoadjuvant treatment are inaccurate. The strength of this study is its detailed histopathological analysis after systematic radical lymphadenectomy, often not available in other reports. To the best of our knowledge no large trial with standardized radical LAD using EUS, CT and integrated PET/CT comparing AEG I-III and GC has been reported in a Western population.

The good results of EUS in our study are not uniformly reproducible in the literature, and some studies demonstrate a high variability for sensitivity $(16.7-96.7 \%)$ and specificity (48.4-100\%). ${ }^{13,32}$ Both EUS and CT generally use a diameter $\geq 1 \mathrm{~cm}$ as a diagnostic criterion for $\mathrm{LN}$ involvement. ${ }^{33}$ $\mathrm{LN}$ size alone, however, is not a reliable indicator in AEG and GC since more than $50 \%$ of resected metastatic LNs are $\leq 5 \mathrm{~mm}$ in diameter. ${ }^{34}$ One study therefore defined all identifiable LNs as metastatic, ${ }^{35}$ and surprisingly this study still reported a sensitivity of $89.5 \%$ and a specificity of $75.0 \%$.

Table 3

$\mathrm{N}$ staging for early versus advanced tumors. $\mathrm{N}$ staging by positron emission tomography and computed tomography (PET-CT): accuracy and predictive values for early and advanced tumors (TNM 7th Edition, AJCC/ UICC). ${ }^{29}$

\begin{tabular}{llll}
\hline & Advanced $(>$ pT1) & Early $(\mathrm{pT} 1)$ & $P$ \\
\hline Sensitivity & 49.5 & 28.6 & 0.2 \\
Specificity & 88.9 & 95 & 0.4 \\
Accuracy & 58.3 & 77.8 & 0.02 \\
PPV & 93.9 & 66.7 & 0.08 \\
NPV & 33.8 & 79.2 & $<0.01$ \\
\hline
\end{tabular}

PPV, positive predictive value; NPV, negative predictive value.
Table 4

Comparison of positron emission tomography and computed tomography (PET-CT) and multidetector spiral computed tomography (MDCT) in the detection of metastases. (A) Overall detection of metastases. (B) Detection of systemic metastases with exclusion of peritoneal carcinomatosis.

\begin{tabular}{llll}
\hline A & PET-CT & MDCT & $P$ \\
\hline Sensitivity & 56.9 & 40.0 & 0.1 \\
Specificity & 98.7 & 98.1 & 1 \\
Accuracy & 88.5 & 83.3 & 0.1 \\
PPV & 93.5 & 88.0 & 0.7 \\
NPV & 87.6 & 82.7 & 0.2 \\
\hline B & PET-CT & MDCT & $P$ \\
\hline Sensitivity & 82.1 & 48.4 & 0.01 \\
Specificity & 98.9 & 98.9 & 1 \\
Accuracy & 96.7 & 91.6 & 0.04 \\
PPV & 92 & 88.2 & 1 \\
NPV & 97.3 & 91.9 & 0.02 \\
\hline
\end{tabular}

PPV, positive predictive value; NPV, negative predictive value.

In the present study, the major advantage of the PET-CT is a good specificity and positive predictive value. The vast majority of previously reported studies were performed with PET only, and showed a high specificity, despite a low sensitivity in gastric ${ }^{32}$ and esophageal cancers. ${ }^{36}$ A possible reason for the reported low to moderate sensitivity of PET is its limited resolution. Current PET scanners have a 4-5mm resolution, ${ }^{35}$ but it has been reported that $15 \%$ of metastatic LNs in gastric cancer have a diameter of $<3 \mathrm{~mm} .{ }^{34}$

PET/CT fusion provides both anatomical and functional information, and theoretically allows more accurate localization of foci with increased ${ }^{18}$ FDG uptake than standalone PET. Our results, however, are in line with published data using conventional PET. ${ }^{14,37-39}$ Despite the combined PET-CT used in our study, the sensitivity remained too low for clinical prediction of regional lymph nodes. This may be a result of the intense uptake of ${ }^{18}$ FDG by the primary tumor that complicates interpretation by obscuring the adjacent regional LN basins. Previously, PET alone demonstrated an improved detection of distant lesions compared to $\mathrm{CT},{ }^{40,41}$ and sensitivities as high as $90 \%$ have been reported in the detection of metastatic LNs at distant sites, including cervical and abdominal locations. ${ }^{14}$ Two recent reports suggest a role for PET-CT in the detection of metastatic disease, but they are retrospective and lack comparison with $\mathrm{CT}$ and/or histology. ${ }^{42,43}$ The only available prospective study involving 113 Western patients found a benefit in about $10 \%$ of the patients compared to CT. ${ }^{44}$ Our data strongly support these findings, especially for tumors with intestinal/mixed differentiation. In contrast, PETCT does not provide an additional benefit in diffuse-type cancers or for exclusion of peritoneal involvement, where diagnostic laparoscopy remains the diagnostic standard.

A recent study in patients with esophageal cancer reported a poor diagnostic performance of a response PETCT after chemoradiation. ${ }^{45}$ This is in line with our results, and we extended our findings to patients with gastric cancer. Importantly, our results show that the initial PET-CT 
scan before neoadjuvant treatment is more accurate for $\mathrm{N}$ staging than the consecutive preoperative PET-CT scan after neoadjuvant treatment, which showed a high falsenegative rate and is therefore not reliable for the prediction of lymph-node status. Despite the shown prognostic information by response evaluation of the primary tumor in the MUNICON II trial, ${ }^{16}$ a restaging PET-CT therefore does not change the surgical strategy or extent of lymphadenectomy.

Based on our results, PET-CT should not be uniformly recommended. For regional $\mathrm{N}$ staging, PET-CT is useful only in patients with AEG tumors or GC with intestinal/ mixed differentiation, where sensitivity and accuracy are clearly better than those of EUS and MDCT. In these patients, PET-CT may help to identify extra-regional lymph nodes for extended surgery. Routine extension of LAD to the para-aortic D3 compartment did not result in an overall survival benefit in GC, and is probably indicated only in selected patients. ${ }^{21}$ Similarly, three-field LAD for esophageal cancer may improve the outcome in selected patients, but is currently also not recommended for routine use. ${ }^{20}$ Radiological staging could be an option to select patients for targeted extension of the LAD since detection is improved by both PET $^{14}$ and PET-CT, as demonstrated. In contrast, sensitivity is insufficient for decision-making in patients with gastric cancer with diffuse-type tumors owing to a low FDG uptake and therefore poor sensitivity. In early tumors, a limited LAD cannot be recommended on the basis of PET-CT. The risk of missing small metastases or micrometastases by PET-CT in these patients is significant, and may have an impact on the patients' survival. ${ }^{46}$

In conclusion, PET-CT improves diagnostic specificity, but does not improve overall accuracy compared to EUS and MDCT, and therefore should not be performed in all patients with AEG or GC. In patients with AEG or GC with intestinal/mixed-type differentiation, PET-CT has a higher specificity and PPV than EUS and MDCT for $\mathrm{N}$ staging, improves the detection rate of extra-regional LNs and systemic metastases, and influences therapeutic strategies. In patients following neoadjuvant treatment, restaging of lymph nodes by PET-CT appears to be too inaccurate.

\section{Conflict of interest statement}

The authors declare no conflict of interest.

\section{Appendix A. Supplementary data}

Supplementary data related to this article can be found at http://dx.doi.org/10.1016/j.ejso.2016.08.020.

\section{References}

1. Siewert JR, Stein HJ. Classification of adenocarcinoma of the oesophagogastric junction. Br J Surg 1998;85:1457-9.
2. Hartgrink HH, Jansen EP, van Grieken NC, van de Velde CJ. Gastric cancer. Lancet 2009;374:477-90.

3. Reynolds JV, Ravi N, Muldoon C, et al. Differential pathologic variables and outcomes across the spectrum of adenocarcinoma of the esophagogastric junction. World J Surg 2010;34:2821-9.

4. Siewert JR, Bottcher K, Stein HJ, Roder JD. Relevant prognostic factors in gastric cancer: ten-year results of the German Gastric Cancer Study. Ann Surg 1998;228:449-61.

5. Hulscher JB, van Sandick JW, de Boer AG, et al. Extended transthoracic resection compared with limited transhiatal resection for adenocarcinoma of the esophagus. N Engl J Med 2002;347:1662-9.

6. Omloo JM, Lagarde SM, Hulscher JB, et al. Extended transthoracic resection compared with limited transhiatal resection for adenocarcinoma of the mid/distal esophagus: five-year survival of a randomized clinical trial. Ann Surg 2007;246:992-1000. discussion-1.

7. Songun I, Putter H, Kranenbarg EM, Sasako M, van de Velde CJ. Surgical treatment of gastric cancer: 15-year follow-up results of the randomised nationwide Dutch D1D2 trial. Lancet Oncol 2010;11:439-49.

8. Hwang SW, Lee DH, Lee SH, et al. Preoperative staging of gastric cancer by endoscopic ultrasonography and multidetector-row computed tomography. J Gastroenterol Hepatol 2010;25:512-8.

9. Stein HJ, Brucher BL, Sendler A, Siewert JR. Esophageal cancer: patient evaluation and pre-treatment staging. Surg Oncol 2001;10:10311.

10. Cordin J, Lehmann K, Schneider PM. Clinical staging of adenocarcinoma of the esophagogastric junction. Recent Results Cancer Res 2010;182:73-83.

11. Bentrem D, Gerdes H, Tang L, Brennan M, Coit D. Clinical correlation of endoscopic ultrasonography with pathologic stage and outcome in patients undergoing curative resection for gastric cancer. Ann Surg Oncol 2007;14:1853-9.

12. Meining A, Dittler HJ, Wolf A, et al. You get what you expect? A critical appraisal of imaging methodology in endosonographic cancer staging. Gut 2002;50:599-603.

13. van Vliet EP, Heijenbrok-Kal MH, Hunink MG, Kuipers EJ, Siersema PD. Staging investigations for oesophageal cancer: a metaanalysis. Br J Cancer 2008;98:547-57.

14. Lerut T, Flamen P, Ectors N, et al. Histopathologic validation of lymph node staging with FDG-PET scan in cancer of the esophagus and gastroesophageal junction: a prospective study based on primary surgery with extensive lymphadenectomy. Ann Surg 2000;232:743-52.

15. Chen J, Cheong JH, Yun MJ, et al. Improvement in preoperative staging of gastric adenocarcinoma with positron emission tomography. Cancer 2005;103:2383-90.

16. Lordick F, Ott K, Krause BJ, et al. PET to assess early metabolic response and to guide treatment of adenocarcinoma of the oesophagogastric junction: the MUNICON phase II trial. Lancet Oncol 2007;8: 797-805.

17. Schneider PM, Metzger R, Schaefer H, et al. Response evaluation by endoscopy, rebiopsy, and endoscopic ultrasound does not accurately predict histopathologic regression after neoadjuvant chemoradiation for esophageal cancer. Ann Surg 2008;248:902-8.

18. Cunningham D, Allum WH, Stenning SP, et al. Perioperative chemotherapy versus surgery alone for resectable gastroesophageal cancer. $N$ Engl J Med 2006;355:11-20.

19. Lerut T, Moons J, Coosemans W, et al. Multidisciplinary treatment of advanced cancer of the esophagus and gastroesophageal junction: a European center's approach. Surg Oncol Clin N Am 2008;17:485502. vii-viii.

20. Lerut T, Nafteux P, Moons J, et al. Three-field lymphadenectomy for carcinoma of the esophagus and gastroesophageal junction in 174 R0 resections: impact on staging, disease-free survival, and outcome: a plea for adaptation of TNM classification in upper-half esophageal carcinoma. Ann Surg 2004;240:962-72. discussion 72-4.

21. Sasako M, Sano T, Yamamoto S, et al. D2 lymphadenectomy alone or with para-aortic nodal dissection for gastric cancer. $N$ Engl $\mathrm{J} \mathrm{Med}$ 2008;359:453-62. 
22. Grotenhuis BA, van Heijl M, Zehetner J, et al. Surgical management of submucosal esophageal cancer: extended or regional lymphadenectomy? Ann Surg 2010;252:823-30.

23. Katai H, Morita S, Saka M, Taniguchi H, Fukagawa T. Long-term outcome after proximal gastrectomy with jejunal interposition for suspected early cancer in the upper third of the stomach. Br J Surg 2010; 97:558-62.

24. Stein HJ, Feith M, Mueller J, Werner M, Siewert JR. Limited resection for early adenocarcinoma in Barrett's esophagus. Ann Surg 2000;232: $733-42$.

25. Saka M, Morita S, Fukagawa T, Katai H. Present and future status of gastric cancer surgery. Jpn J Clin Oncol 2011;41:307-13.

26. Al-Batran SE, Hartmann JT, Hofheinz R, et al. Biweekly fluorouracil, leucovorin, oxaliplatin, and docetaxel (FLOT) for patients with metastatic adenocarcinoma of the stomach or esophagogastric junction: a phase II trial of the Arbeitsgemeinschaft Internistische Onkologie. Ann Oncol 2008:19:1882-7.

27. van Hagen P, Hulshof MC, van Lanschot JJ, et al. Preoperative chemoradiotherapy for esophageal or junctional cancer. N Engl J Med 2012 366:2074-84.

28. The Japanese Gastric Cancer Association. Japanese classification of gastric carcinoma - 2nd English edition. Gastric Cancer 1998;10-24.

29. Wittekind C, Meyer H, editors. TNM classification of malignant tumors. 7th ed. Wiley; 2010.

30. Ganpathi IS, So JB, Ho KY. Endoscopic ultrasonography for gastric cancer: does it influence treatment? Surg Endosc 2006;20:559-62.

31. Davies J, Chalmers AG, Sue-Ling HM, et al. Spiral computed tomography and operative staging of gastric carcinoma: a comparison with histopathological staging. Gut 1997;41:314-9.

32. Kwee RM, Kwee TC. Imaging in assessing lymph node status in gastric cancer. Gastric Cancer 2009;12:6-22.

33. Choi J, Kim SG, Kim JS, Jung HC, Song IS. Comparison of endoscopic ultrasonography (EUS), positron emission tomography (PET), and computed tomography (CT) in the preoperative locoregional staging of resectable esophageal cancer. Surg Endosc 2010;24:1380-6.

34. Monig SP, Schroder W, Baldus SE, Holscher AH. Preoperative lymphnode staging in gastrointestinal cancer-correlation between size and tumor stage. Onkologie 2002;25:342-4.

35. Stabile Ianora AA, Pedote P, Scardapane A, et al. Preoperative staging of gastric carcinoma with multidetector spiral CT. Radiol Med 2003; 106:467-80.
36. van Westreenen HL, Westerterp M, Bossuyt PM, et al. Systematic review of the staging performance of $18 \mathrm{~F}$-fluorodeoxyglucose positron emission tomography in esophageal cancer. J Clin Oncol 2004;22: 3805-12.

37. Yun M, Lim JS, Noh SH, et al. Lymph node staging of gastric cancer using (18)F-FDG PET: a comparison study with CT. J Nucl Med 2005; 46:1582-8.

38. Hur H, Kim SH, Kim W, et al. The efficacy of preoperative PET/CT for prediction of curability in surgery for locally advanced gastric carcinoma. World J Surg Oncol 2010;8:86.

39. Kim EY, Lee WJ, Choi D, et al. The value of PET/CT for preoperative staging of advanced gastric cancer: comparison with contrastenhanced CT. Eur J Radiol 2011 Aug;79(2):183-8.

40. Flamen P, Lerut A, Van Cutsem E, et al. Utility of positron emission tomography for the staging of patients with potentially operable esophageal carcinoma. J Clin Oncol 2000;18:3202-10.

41. Malik V, Keogan M, Gilham C, et al. FDG-PET scanning in the management of cancer of the oesophagus and oesophagogastric junction: early experience with 100 consecutive cases. Ir J Med Sci 2006;175: $48-54$.

42. Blencowe NS, Whistance RN, Strong S, et al. Evaluating the role of fluorodeoxyglucose positron emission tomography-computed tomography in multi-disciplinary team recommendations for oesophagogastric cancer. Br J Cancer 2013;109:1445-50.

43. Bunting DM, Lai WW, Berrisford RG, et al. Positron emission tomography-computed tomography in oesophageal cancer staging: a tailored approach. World J Surg 2015 Apr;39(4):1000-7.

44. Smyth E, Schoder H, Strong VE, et al. A prospective evaluation of the utility of 2-deoxy-2-[(18) F]fluoro-D-glucose positron emission tomography and computed tomography in staging locally advanced gastric cancer. Cancer 2012;118:5481-8.

45. Elliott JA, O'Farrell NJ, King S, et al. Value of CT-PET after neoadjuvant chemoradiation in the prediction of histological tumour regression, nodal status and survival in oesophageal adenocarcinoma. $\mathrm{Br} \mathrm{J}$ Surg 2014;101:1702-11.

46. Izbicki JR, Hosch SB, Pichlmeier U, et al. Prognostic value of immunohistochemically identifiable tumor cells in lymph nodes of patients with completely resected esophageal cancer. N Engl J Med 1997;337: $1188-94$. 